\title{
Ser antropóloga \\ entre local e global
}

DoI

http://dx.doi.org/10.11606/ 2179-0892.ra.2017.141649

\section{Esmeralda Mariano}

- Universidade Eduardo Mondlane / Maputo, Moçambique

$\checkmark$ esmeraldamariano3@gmail.com

\section{RESUMO}

Este artigo explora os desdobramentos e a complexidade do ser antropóloga "local" e "global", fazendo o esforço de ultrapassar o paradigma dicotômico resultante de processos históricos e políticos, que colocam atores sociais em espaços delimitados e localizados. Estes pressupostos são explorados a partir da história do meu nome, combinando experiências intersubjetivas e a reflexividade em pesquisas sobre a sexualidade em contextos de Moçambique.

PalavRAS-ChaVE

Antropólogo nativo, local e global, experiências subjetivas. 


\section{INTRODUÇÃO}

A proposta de reflexão "ser antropóloga entre local e global", se enquadra num tema que não é novo no seio dos estudos antropológicos, relativo à problematização da distinção entre o "nativo" e o "não-nativo". À primeira vista, o conceito de «nativo» no discurso antropológico atual pode não parecer estar relacionado com pretensões de hierarquia, mas, no vocabulário de missionários, exploradores, administradores coloniais e também antropólogos, o termo "nativo" manteve-se como moeda de troca, servindo como substituto do termo "primitivo", com o qual sentimos um certo desconforto (Appadurai, 1996).

A utilização, no âmbito da antropologia, dos termos nativo/local e não-nativo/global, permite-nos refletir sobre o desequilíbrio na legitimidade de representar a alteridade. Estes termos são usados implícita ou explicitamente nas relações entre o antropólogo e o nativo (sujeito-objeto de estudo), ou seja, por um lado, entre o observador e o observado e, por outro, nas relações entre os antropólogos provenientes de lugares, escolas e experiências diferenciadas. No seu artigo "O nativo relativo", Viveiros de Castro chamou a nossa atenção para o fato da Antropologia colocar em discussão sobre quem somos "nós", evidenciando que esse "nós" esconde tantos outros, havendo, por isso, a necessidade de se lutar contra os "grandes divisores" - nós e os outros, ocidentais e os não ocidentais, e fazer proliferar as pequenas multiplicidades (Viveiros de Castro, 2010). Um outro aspecto que retomo em Viveiros de Castro, e desenvolvo nesta análise, é que o conhecimento antropológico é imediatamente uma relação social, e toda relação é uma transformação.

O meu ponto de partida para esta reflexão, parte das designações e distinções entre investigadora local e internacional, feitas nos projetos de pesquisa e de consultoria realizados no Moçambique contemporâneo, que envolvem atores e investigadores de diferentes partes do mundo. O investigador moçambicano, se faz parte de uma equipe, é designado de local, com papéis frequentemente definidos pelo investigador internacional, e com retribuição diferenciada - o que implicitamente contém um juízo de valor, mesmo entre colegas bem-intencionados em estabelecer relações de paridade e mutualidade. Concordo, portanto, com o antropólogo camaronês Paul Nkwi, quando afirma que a demanda de consultorias tem produzido uma forte pressão para a afirmação da identidade dos antropólogos, do seu papel social e epistêmico (Nkwi 2008:207).

É neste sentido que pretendo refletir não apenas sobre o uso do termo "local" subjacente a relações assimétricas e de privilégio, mas também dialogar com os trabalhos de pesquisadores de vários contextos, os quais revelam que pensar no antropólogo "nativo" ou "não-nativo", como categorias estanques e estáveis, 
mostra-se irrelevante, inviável e redutor para compreender fenômenos que na maioria das vezes se interpenetram (Narayan, 1993).

\section{PECULIARIDADES E LIMITES DA DISTINÇÃo “NATIVO" E "NÃO-NATIVO"}

Vários autores apontam para "nativo", "indígena" ou "local" como termos imprecisos, que apresentam resquícios dos tempos da colonização, nos quais a disciplina antropológica foi forjada, na altura em que os nativos eram tidos como "genuínos" (Narayan, 1993; Appadurai, 1996; Mbembe, 2001; Kuper, 2002).

Os antropólogos raramente pensam em si mesmos como nativos de um lugar, porque o ser nativo significa muito mais do que ser de um lugar. O termo é usado para grupos que pertencem a partes do mundo distantes e distintas das metrópoles ocidentais (Appadurai, 1996).

Ser local ou global, dependendo das situações, confere prestígio e privilégio, exclusividade no acesso aos recursos e ao monopólio sobre a validade científica (Nkwi, 2008). Na prática, apesar que o antropólogo "nativo" dê uma importante contribuição para a produção científica, baseada na sua origem e qualificação profissional, é pouco reconhecido, sendo frequentemente utilizado como contato para conseguir a autorização da investigação e fonte de conhecimento contextual. Assim, os saberes produzidos na dita periferia estão destinados a permanecer escondidos, a menos que satisfaçam os padrões e expectativas do centro, onde os acadêmicos influentes podem decidir a que tipo de conhecimento se deve conferir autoridade e atenção (Narayan, 1993; Nkwi, 2008; Ribeiro e Escobar, 2008).

Em direção a uma antropologia não apenas cimentada na crítica à hegemonia do centro do mundo ou do Ocidente, mas que também refute as falsidades e preconceitos da construção universal dos africanos, por exemplo, faz mais sentido considerar a porosidade das fronteiras e a existência de espaços de poder. Podemos, assim, pensar num ser-antropólogo a partir de diversas e interconectadas práticas, na perspectiva de se abrir o caminho para a construção de um estilo próprio (Mbembe, 2001:175). No seu último livro, Achille Mbembe (2016) reflete sobre "políticas da inimizade", o tema da fronteira e sua "evolução" ao longo do tempo volta a emergir, para mostrar que o sentimento de pertença é reinventado cada vez mais através de disputas e manipulações sobre o que pertence a quem, pressuposto válido para esta análise.

Minha trajetória de vida, minhas vivências em contextos urbanos e rurais em Moçambique e na Europa, educada e socializada entre valores tradicionais e modernos, levou-me a questionar o sentido do ser antropóloga "nativa" ou "local". A formação nas universidades da Itália, Noruega e Bélgica, dotou-me de referenciais para compreender os "deslocamentos culturais" derivantes de cons- 
tantes mudanças sociais e dinâmicas do quotidiano. As pesquisas realizadas em Moçambique e a relação estabelecida com os meus interlocutores, fizeram gradualmente emergir sentimentos ao mesmo tempo de afinidade e alienação sobre a visão do mundo e a consciência das limitações dos quadros teóricos e metodológicos apreendidos. Em relação ao antropólogo global (outsider), a definição do antropólogo nativo (insider) - como quem partilha lugares de vivência e supostamente a raiz cultural dos seus interlocutores-, a partir do momento em que o termo "local" assume múltiplos sentidos, mostra-se fluída e cada vez mais instável. Aliás, falar de raiz cultural e do conceito de cultura, merece também uma permanente análise crítica. Lembro-me, por exemplo, numa das aulas na Universidade de Bergen (Noruega, 2001), da forma brilhante como o Professor Frederik Barth chamou-nos a atenção para as limitações da generalização da categoria "cultura", porque "o material da cultura" pode não ser um bem comum compartilhado, uma vez que é variável em relação ao mundo, aos grupos e às ações sociais, podendo ser verdadeiro em alguns casos e não verdadeiro em outros. Acrescento, ainda, que a educação, sexo, gênero, classe, raça e outras variadas categorias e designações sociais, ou simplesmente a duração e intensidade dos contatos intersubjetivos, em diferentes espaços e momentos, também alteram os sentidos através dos quais se etiqueta o "nativo" ou "não-nativo".

O meu nome e as experiências de pesquisa sobre sexualidade em Moçambique podem exemplificar esses desdobramentos e interpenetração entre o local e global. Dependendo do contexto e dos campos de poder, fazemos escolhas ou simplesmente somos forçados a aceitar outras identidades em constante transformação. Em contextos geográficos diferentes, dentro e fora de Moçambique, a evocação do meu nome e sobrenome serviu a mim e meus interlocutores para repensar as origens étnico linguísticas, para estabelecer a comunicação em zonas de contato e de afinidades culturais, e, nalguns casos, para (des)legitimar uma aparente ideia de natividade e localidade.

No campo de pesquisa, particularmente no sul de Moçambique, em inúmeras ocasiões meus interlocutores falantes de ronga e changana (pertencentes ao grupo tsonga), com diferentes expectativas e curiosidades, perguntaram-me qual era a minha raça, referindo-se às origens da minha família, ao nome e a língua bantu do meu grupo. No meu entendimento, a referência à raça, cingia-se não a cor da pele ou atributos físicos, mas ao pertencimento a um grupo étnico-linguístico africano-moçambicano. Concretamente, a questão era se eu era changana ou ronga, porque meu nome não espelhava qualquer origem bantu. Mais que um questionamento morfológico, a questão era ontológica. Meu nome (de origem portuguesa) e o meu limitado domínio da língua changana pareciam dissociar-se da estrutura sociocultural dos meus interlocutores e, portanto, limitavam-me a possibilidade de ser nativa. 
Descrevo e analiso nas páginas seguintes questionamentos do meu nome de registo, que também na Europa revelou-se deslocado, fora de lugar, e não verdadeiramente nativo. De onde eu seria então nativa? Do lugar onde nasci? De acordo com a lei da nacionalidade? Qual o papel da cor/raça e da etnicidade na definição do local? Sendo natural de $X$, filha de $A$ e $B$, que viveu $Y$ anos num lugar em contato com A, B, C, D... e mais tarde em tantos outros contextos, seria nativo em relação a quem? Definido por quem e quais os critérios? E por quanto tempo se permanece nativo? Os sentimentos de parcialidade, fragmentaridade e, ao mesmo tempo, conexão com o global, no meu trabalho com antropólogos de outras paragens e influências teórico-epistemológicas que transcendem as fronteiras de Moçambique, levaram-me a um conjunto de condições que abriram meu horizonte para explorar e refletir sobre o binômio nativo e não-nativo.

\section{UM NOME LOCAL E GLOBAL}

Como sustenta Bruno Latour, local e global, são conceitos bem adaptados às superfícies e à geometria, mas inadequados para as redes e a topologia (Latour 1994: 116), os nomes são também, deformados e transformados. Metodologicamente, o "distanciamento" é crucial para estudar culturas diferentes das nossas e o material da cultura. Como antropólogos, temos que enfrentar a tarefa ainda mais difícil de criar distância suficiente entre os nossos espaços familiares e as nossas culturas (Ohnuki-Tierney, 1984).

Ao trazer o meu nome pessoal para esta discussão, como um material da cultura, não pretendo de algum modo assumir uma atitude narcisista, tampouco levar o leitor a entender esta análise como fruto de uma investigação aprofundada e apurada. Trata-se de um exercício de autoconsciência, uma reflexão ainda em curso, iniciada a partir de contatos com pessoas em contextos culturais diferenciados. À semelhança da discussão acerca do nativo e do não nativo, a questão dos nomes é inesgotável, algo vivo, sobre a vida da pessoa como um ser social (Pina Cabral, 2008).

Esmeralda (Celeste Mariano) é um nome bonito, é nome de uma pedra preciosa, mas não é um nome africano!? Por que Mariano? Qual é o teu nome africano? O teu verdadeiro nome? Esses foram questionamentos frequentes e insistentes nos meus primeiros passos na Europa (Itália). Este tipo de interrogação chamou-me à consciência sobre o sentido de pertença a uma cultura viva e híbrida, tradicional e contemporânea. Como a iniciação antropológica implica a adoção de um ponto de vista capaz de libertar, o quanto mais possível, para compreender a nós mesmo e a alteridade, esse momento levou-me a prestar mais atenção em nomes, no indivíduo, na história, na identidade e na existência como partes da reflexão sobre o eu-outro, sobre os cruzamentos e deslocamen- 
tos, temas privilegiados da antropologia. A partir de memórias vividas e vivas, meu nome serviu para explicar e representar o sentido da minha existência, traçar meu ciclo de vida e a minha visão do mundo, e demonstrar que, como indivíduos, somos um produto híbrido, oscilando entre uma ordem tida como mais formal e outra tida como mais tradicional.

Alguns estudos mostram que os processos de nomeação não são estáticos nem homogêneos em todas culturas. Gregório Firmino, no seu artigo acerca dos antropônimos usados entre o grupo étnico vatonga ${ }^{7}$ de Inhambane, no sul de Moçambique, com afinidades com a minha cultura de origem, realça o carácter criativo, heterogêneo e dinâmico, cujas inovações são associadas a contingências sócio-históricas do Moçambique contemporâneo (Firmino 2008: 139). Na verdade, os cruzamentos culturais, que se sobrepõem, se complementam e se alteram, por vezes ocultam a ambivalência entre o tradicional e o moderno. A escolha e a atribuição do nome inscrevem-se, portanto, num quadro histórico em contínua transformação, de invenção social, e narram as ligações, rupturas e descontinuidades entre passado, presente e futuro, entre vida e morte.

De fato, algumas vezes os nomes atribuídos logo após o nascimento são abandonados em fases diferentes da vida, outros permanecem, alguns são públicos, outros secretos e de circulação restrita (Trajano Filho, 2008).

Um dos momentos marcantes da história colonial em Moçambique, resultante do processo de assimilação, foi a adoção de nomes portugueses, pelo menos como nomes próprios, embora não significando necessariamente rejeição dos nomes africanos "tradicionais" (Firmino, 2008: 134-136). O nome Esmeralda, escolhido pelos meus pais, simboliza o processo de civilização, o modelo idealizado de convivência entre brancos e negros, colonizadores e colonizados, no contexto da assimilação colonial. Todavia, a essência da política da assimilação "consistia em des-substancializar e estetizar a diferença, ao menos para uma categoria de nativos (les évolués), cooptados para o espaço da modernidade por terem sido 'convertidos' e 'cultivados', ou seja, tornados passíveis de se encaixarem na ideia de cidadania e do gozo dos direitos civis" (Mbembe, 2001: 178).

Este princípio estético e de conversão, de passagem da tradição à modernidade, de hibridização, na nossa família, tinha iniciado com o meu bisavó paterno, Mharriani Whate. O processo de apagamento e de renomeação enquadra-se no período colonial, quando as medidas legislativas levadas a cabo no início do século XX tinham como objetivo definir dois tipos de população, promulgados com o Código de Assistência ao Nativo de 1921, posteriormente abolido em 1961, e substituído pelo Estatuto dos Indígenas - quando se declarava que todos os habitantes nativos (naturais) de Moçambique, Angola e Guiné eram cidadãos portugueses de pleno direito (Mondlane, 1995). Na verdade,
1 "A palavra vatonga, tal como todos os nomes nas línguas bantu, contém um radical-tonga, a que se junta o prefixo do plural va-para designar pessoas de origem tonga" (Firmino, 2008). 0 grupo etnolinguistico tonga ou também designado tsonga, que inclui muitos outros grupos, no sul de Moçambique é de origem bantu, caracterizado por uma organização social que se assenta numa descendência patrilinear. 
estes princípios eram mais teóricos que práticos. Eduardo Mondlane, antropólogo e primeiro presidente da Frente de Libertação de Moçambique (FRELIMO), partido que levou à independência nacional em 1975, na sua incontornável obra The Struggle for Mozambique (1969), mais tarde traduzida para português e editada em Moçambique em 1995, dá uma ideia da construção do "nativo" no contexto colonial:

O Código de Assistência ao Nativo de 1921, definiu o a fricano civilizado como aquele que sabia falar português, que estava desligado de todos os costumes tribais, e que tinha emprego regular e remunerado. Este seria considerado como verdadeiro português, (...). O regime de indigenato foi implantado em todos os territórios africanos. A população a fricana ficou dividida em duas categorias distintas, indígenas (africanos não-assimilados) e não indígenas (qualquer um que tivesse plena cidadania portuguesa, incluindo os assimilados a fricanos, embora na prática estes fossem muitas vezes considerados como pertencendo a uma terceira categoria). O indígena não tinha cidadania, era obrigado a trazer uma Caderneta Indígena (cartão de identidade), e estava sujeito a todos os regulamentos do regime do indigenato, que lhe impunha obrigações de trabalho, não Ihe permitia o acesso a certas áreas das cidades depois de escurecer, e restringia-o a alguns poucos lugares de divertimento, e até os cinemas para indigenas passavam filmes cuidadosamente censurados. O não indígena tinha, teoricamente, todos os privilégios que acompanhavam a cidadania portuguesa (Mondlane, 1995: 43).

A análise de Eduardo Mondlane, está em consonância com a história da minha família, na qual a assimilação significou a não aceitação do africano como africano, mas também não europeu. O nome do meu bisavô Mharriani (que significa, em tonga, armadilha) ficou deformado em Mariano, enquanto Whate, o sobrenome que distinguia a família e a linhagem, foi omitido e cancelado do registo oficial, herança que seus descendentes assumiram.

Com a independência de Moçambique em 1975, em várias ocasiões a família discutiu e pensou na possibilidade de recuperação do sobrenome, para constar nos documentos de identidade oficial (registros), como um reconhecimento público, reatando a ligação com os antepassados e com a cultura africana dos tonga. O desejo e aspiração de colocar em papel o nome dissipou-se devido à complexidade dos processos burocráticos. Nem por isso os descendentes perderam a ligação simbólica e espiritual com as origens. Ainda hoje, os curandeiros quando solicitadas por pessoas de variadas classes, residentes em áreas rurais ou urbanas, para tratar e aliviar suas aflições em determinados momentos das suas vidas, no ato de invocação aos antepassados, a referência aos nomes dos antepassados da família emerge. 
Numa perspectiva mais ampla, o curandeiro ou também designado "médico tradicional" é socialmente reconhecido como capaz de cuidar e tratar do corpo fisicopsicossocial, e de influenciar no restabelecimento das relações familiares interrompidas e da ordem cosmológica. Entre os falantes de tonga, são denominados nyanga (pl. tinyanga). Nesta categoria incluem-se os ervanários, os espíritos médiuns, adivinhos e exorcistas (ver Honwana, 2002). Os tinyanga, são os intermediários entre os vivos e os mortos, ativadores da memória individual e coletiva, com poderes para interpretar passado e presente. Estimulam o indivíduo a estabelecer a conexão com as "origens", reforçando o poder dos espíritos dos antepassados, os quais constituem fonte do conhecimento e de poder de diagnóstico e terapêutico, bem como garantem proteção e bem-estar (Mariano, 2014). Embora entre as elites urbanizadas não se admita abertamente que se consulte o curandeiro, por vergonha e receio de se ser conotado como supersticioso e obscurantista, talvez com menos possibilidades de ser global, vários curandeiros homens e mulheres, durante as pesquisas realizadas, relataram que, com muita frequência, indivíduos de todas as classes e condições sociais - incluindo médicos, ministros, sacerdotes, brancos, negros e mestiços - que procuram sorte, ascensão nas suas carreiras profissionais e cuidados de saúde, procuram seus serviços. No dia a dia, a força vital e presença dos espíritos manifesta-se na forma como estes influenciam o destino do indivíduo, protegendo-o ou prejudicando-o de diversas maneiras e em fases da vida do indivíduo (Mariano, 2014). Os espíritos de família (tinguluve ${ }^{2}$ ) ou espíritos da casa (svikwembu sva la kaya) são termos usados alternadamente. A comunicação com estes pode ser feita em casa - espaço fechado, (espaço paterno), ou ao ar livre (em árvores sagradas), sempre que se pretende alcançar algo importante na vida (bem-estar, sucesso nos negócios, emprego...), ou quando algo está prestes a ocorrer, tal como uma viagem ou um casamento, ou quando simplesmente se procura proteção contra eventual infortúnio. Através da invocação dos antepassados de quem se presta e de quem se recebe os cuidados e a proteção, presume-se que haja transferência de energias e de forças vitais produzindo um efeito positivo sobre os indivíduos (Mariano, 2014). “Os espíritos agradecem a quem respeita a tradição e ajuda que ela se mantenha viva. A saúde, as finanças, a sorte, o emprego e os caminhos que se abrem são sinais de bênção dos espíritos dos ancestrais" (Cossa, 2014:68).

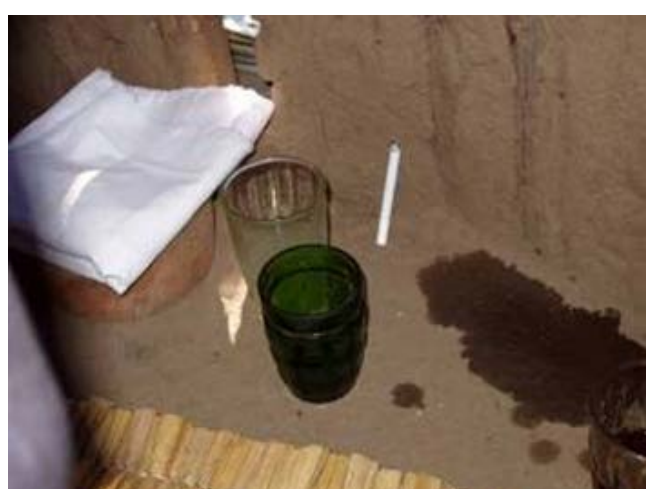

2 Tinguluve (pl. de nguluve), literalmente "porcos-suínos" no sul de Moçambique, em línguas tonga designa os espíritos linhageiros.

\section{Figura 1}

Comunicação com os espíritos. Província de Inhambane, 2007. Foto: E. Mariano. 
Tecido branco, cigarro ou tabaco avulso, bebida branca ou transparente, vinho branco, destilado de seiva da palma, ou simplesmente mistura de água e farinha de algum cereal, são alguns dos produtos oferecido no preanúncio da comunicação, ritual designado kuphalha no sul de Moçambique. Uma parte das bebidas é versada no chão em oferta aos espíritos, os nomes destes são invocados e as preces feitas pelo sujeito. Na comunicação entre o indivíduo e seus espíritos, sendo o espírito extensão da pessoa, o nome do seu homônimo e da família-apelido devem ser pronunciados.

No meu caso, o segundo nome, Celeste, tem o seu correspondente "tradicional" em Gothea, nome da mãe do meu avô materno. O nome Gothea Mwabanyne, conhecido e usado exclusivamente entre os membros da família da minha mãe, constitui um elo de ligação com os antepassados e é a chave de acesso ao espírito protetor.

O estudo que realizei sobre a infertilidade no sul de Moçambique (Mariano, 2001) explica como a rotura na relação entre espírito e corpo é sinalizada, mostrando a ausência da proteção dos antepassados e suas implicações. No estudo, apresentei o caso de Felismina, de 30 anos de idade, que era a única mulher de sua casa sem filhos. Estava no segundo casamento, com experiências de vários abortos espontâneos e morte de um filho. Ela associava sua infertilidade a desvios sociais que haviam marcado sua vida sem filhos. De acordo com o curandeiro por ela consultado, a não interpelação dos antepassados no processo de atribuição do nome do seu filho foi a causa da morte da criança.

Quando o meu filho ainda estava vivo, não tinh leite suficiente para o amamentar, porque havia desentendimento entre a minha família e o pai da criança por causa da incorreta a tribuição do nome. Os espíritos podem secar o leite. Os espíritos da minha família puniram-me, porque a família do pai da criança impôs que se atribuísse o nome da sua família sem estarmos formalmente casados (Mariano, 2009:33).

A atribuição à criança do nome dos antepassados assegura que estes sejam sempre recordados (Bagnol, 2006:11) e perenizados. Dar o nome do antepassado é uma forma de o honrar, pois a criança passa a representar o seu espírito. É importante não só para a própria criança, como também a família. Uma escolha errada do nome pode causar infortúnios e doenças para a própria criança, inclusivamente a morte, como revelado no caso de Felismina (Mariano, 2009: 34).

Nos processos de atribuição dos nomes, para além da referência aos espíritos dos antepassados, outros agentes de aculturação determinam hoje 
as escolhas e as preferências. Nomes de atores das telenovelas e de músicos de sucesso ocupam o imaginário coletivo das pessoas, que vão incorporando novos valores. Importa realçar que as inovações, em muitos casos, não representam uma alteração no ethos sociocultural do sul de Moçambique, na medida em que alguns valores persistem e absorvem novos elementos (Firmino, 2008:138).

Algumas vezes, em pesquisas realizadas no sul de Moçambique, particularmente entre famílias urbanizadas, meus interlocutores explicaram que a preferência por um nome não africano deve-se ao medo dos espíritos dos antepassados, os quais podem perturbar e influenciar negativamente a vida do indivíduo que carrega o seu nome. A resistência do indivíduo ao controle social, caso não adote o nome de um antepassado, é sentida como a tentativa de cancelamento da memória ancestral e coletiva. Ao mesmo tempo, o nome do antepassado é a metonímia do protetor e do destino do indivíduo. No caso de Felismina, ela se confrontou com uma situação para a qual não encontrou solução positiva possível, permanecendo na condição de infertilidade. Não se atreveu a atribuir a seu filho o nome dos espíritos do marido, temendo a reação dos seus próprios espíritos, mas também receou atribuir o nome dos espíritos de sua família, por temer a ira dos espíritos do marido no espaço onde residia, no meio rural (Mariano, 2009).

Em contrapartida, a elite urbana atribui outros nomes africanos, numa tentativa de afirmação indentitária de ligação à África. Mas qual África? O que representa África para um africano? Achille Mbembe chama-nos mais uma vez a atenção que África é a visão do mundo em que a vida não é apenas o campo onde a existência do indivíduo se desenvolve na prática, mas o mundo onde se exerce a existência - isto é, vive-se a vida e enfrenta-se as várias formas da morte (Mbembe, 2001).

Os fenômenos de enculturação e desculturalização são de fato muito complexos, deixando na penumbra aspectos que se tornam evidentes em momentos de crise e de aflição individual, que exigem um esforço de conhecimento e interpretação. O nome, sobre o qual pouco se pensa ontologicamente é "bom para pensar" e conhecer. O nome não é apenas para denotar e classificar, mas também constituiu um universo de reconhecimento de relações constantes e auspiciáveis, ao qual a linguagem e as diferentes formas de comunicação vão dando sentido, alterando de acordo com as diferentes circunstâncias. Especificamente, por meio do nome se pode restabelecer a continuidade da comunicação entre os antepassados e indivíduos, numa realidade em que os sujeitos são gerados e geradores de múltiplas identidades, mantendo viva a tradição (não na sua forma), na contemporaneidade em contínua transformação. 


\section{ALTERIDADE E ENTENDIMENTOS ENTRE UMA ANTROPÓLOGA “LOCAL" E AS MULHERES EM TETE}

A minha incursão em campos femininos íntimos e sensíveis ganhou mais profundidade e complexidade no contexto em que o flagelo do HIV/Aids levava diferentes atores (acadêmicos, decisores políticos, organizações governamentais e não, a nível nacional e internacional, ativistas e da sociedade civil) a um olhar mais atento (embora com peso diferenciado) à subjetividade, à construção do corpo e da sexualidade. A "doença do século", tal como foi chamada, é ainda hoje a maior ameaça para a vida de cada pessoa e família moçambicana e está intrinsecamente associada à sexualidade e à moralidade, porque esta doença, como salientaram alguns testemunhos, "entra" no corpo através do sexo. Como qualquer transtorno físico e psicológico, a doença deixa sinais visíveis no corpo físico-individual e social, levando a constantes ressignificações culturais em contextos sociais particulares. Assim, o corpo na sua interioridade e exterioridade remete-nos à sua contemplação, admiração ou suspeita (Mariano, 2005). Scheper-Hughes (2000:281-292) põe em causa o olhar clínico e biomédico, pelo qual o corpo é reduzido a pequenas partículas invisíveis (no caso do vírus), assim como a epidemiologia, afastando-se do indivíduo para olhar os grupos sociais e estudar os organismos e os "comportamentos de alto risco". A perspectiva crítica da antropologia médica, ao contrário, transcende o olhar fixo do corpo físico e os comportamentos isoladamente para explorar holisticamente o seu redor (ambiente e as redes das relações sociais e políticas) e o interior (experiências, emoções e sentimentos), o realmente vivido e experiencial de corpos que sofrem.

O enfoque no indivíduo como um ser monolítico e isolado, e a doença como entidade biológica, mostra-se precário, assim como os esforços feitos pela ciência moderna são insuficientes para responder ao recrudescimento desta pandemia, se nos recordarmos que, desde a descoberta do primeiro caso de HIV/Aids nos meados dos anos 80 , Moçambique continua sendo um dos países com maior número de casos no mundo. Segundo o Inquérito de Indicadores de Imunização, Malária e HIV/Aids em Moçambique (IMASIDA, 2015), a nível nacional, a prevalência do HIV subiu de $11.5 \%$ em 2009 para $13.2 \%$ em 2015 . Em 2004, de acordo com a ronda de vigilância epidemiológica à prevalência do HIV, a província de Tete tinha uma taxa elevada, de 16.6\%, embora inferior comparativamente à região sul de Moçambique (Maputo, Gaza e Inhambane), estimada em $18.1 \%$ (MISAU, 2005). Atualmente, a província de Tete regista a menor prevalência, com $5.2 \%$, enquanto a província de Gaza, no sul do país, tem a taxa mais elevada, com 24.4\% (IMASIDA, 2015).

Não pretendo aqui analisar as razões dessas reduções e da abismal diferença num espaço temporal de dez anos, mas importa apontar que as formas como a 
epidemia aparece e desaparece no espaço e no tempo, bem como o fato de que a doença escolhe suas vítimas, evidentemente, não tem apenas uma explicação bacteriológica (Bounan, 2004: 31-35). Um conjunto de fatores ambientais, guerra, pobreza, educação, desnutrição, fragilidade física e psicológica, e a qualidade da vida são causas reais da explosão epidêmica que contribuem para a não redução dos efeitos imunodepressores (Mariano, 2005: 1).

Foi no contexto em que epidemia se constituiu como preocupação a nível local e global que, entre 2005 e 2007 , que realizou-se uma pesquisa internacional envolvendo quatro países: Tailândia, Indonésia, África do Sul e Moçambique, intitulada "Cénero, Sexualidade e Práticas Vaginais". Em Moçambique, o estudo, coordenado pela Organização Mundial da Saúde (OMS) em colaboração com o Ministério da Saúde (MISAU), foi realizado na província de Tete, na altura com a prevalência do HIV/Aids elevada (16.6\%), e com evidências de práticas vaginais potencialmente correlatas com a pandemia (INE, 2013). Cientistas sociais (particularmente os/as antropólogos/as) empenharam-se em documentar e analisar as práticas culturais que contribuíam para a disseminação contínua do HIV, bem como as relações sexuais múltiplas desprotegidas, especialmente entre jovens em contextos urbanos e rurais, entre profissionais do sexo, migrantes, prisioneiros, etc. (Loforte, 2003; Matsinhe, 2005; Manuel, 2009; Groes-Green, 2011).

Para o entendimento da sexualidade entre as mulheres da província de Tete, adotamos a perspectiva êmica (dos sujeitos) e, na esteira de Michel Foucault, um enfoque aos fatores que afetam a sexualidade (o clima, a alimentação), a ética dos prazeres, as interconexões entre a sexualidade e a saúde e os mecanismos de gestão da sexualidade que garantem a "arte de viver" na sociedade (Foucault, 1984:139). Procurava-se ver os desdobramentos da sexualidade e da doença, o discurso sobre a alteridade, quer seja feita pelo nativo, quer pelo não-nativo. No âmbito da epidemia de Aids, a imagem do "outro" como depositante da doença tende a reificar e a ser uma fonte de perigo (Cood, 1996:76). Mesmo com diferentes lentes e perspectivas disciplinares variadas, por exemplo, entre os saberes biomédicos e antropológicos, o binômio "doença experiência" e "doença patologia" mostra os divisores entre nós e os outros, em vez de um enfoque sobre as multiplicidades do "eu" do "nós", como acautelou (Viveiros de Castro, 2010).

Na mesma linha deste autor, Cristiano Matsinhe (2005), ao explorar as relações entre as agências de desenvolvimento e a sociedade moçambicana no caso do HIV/Aids, destaca o lugar do corpo-subjetivo no contexto da doença. Matsinhe, chama atenção para os limites da biomedicina relativamente à sua postura hierarquizante dos valores em detrimento da "outra" medicina, a "tradicional", em vez de instituir a coexistência dos sistemas cognitivos, apesar de ambos se fundirem em cosmologias intercambiantes, comunicantes e competitivas (Matsinhe, 2005: 153). Nesta divisória enquadram-se também os binômios 
tradicional/moderno, ou cultural/biológico, na atribuição das causas, prevenção e tratamento da doença, remetidas a um ou a outro espaço.

No caso concreto dos aspectos culturais, as práticas vaginas foram pensadas do ponto de vista ético (objetivo) em correlação ao HIV e Aids. Nesse debate, a cultura, de fato, tornou-se um novo bode expiatório, pelo uso exacerbado do conceito, que reconduz à corresponsabilização do alto índice de contaminação e ineficiência da prevenção biomédica. As inúmeras pesquisas patrocinadas pela sociedade civil e pelas agências multilaterais de desenvolvimento denunciam todos os preceitos e práticas culturais que, a seu ver, condenam as mulheres a uma ordem androcêntrica, bem como pressionam para que tais preceitos e práticas sejam combatidos vigorosamente (Cossa, 2014:30). Segone Cossa, no seu ousado estudo sobre os ritos de iniciação feminina em Moçambique, questiona a relevância do uso de conceitos e teorias criadas no Ocidente para explicar as desigualdades e hierarquias comunitárias com base na distinção morfológica e simbólica do sexo. O autor traz à superfície categorias e conceitos êmicos (subjetivos) que possibilitam uma ressignificação e releitura das relações assimétricas entre pessoas pertencentes ao mesmo grupo étnico/comunitário. Na mesma linha, critica a forma como são imputadas determinadas funções aos ritos de iniciação feminina, "como se existissem apenas para manter uma hegemonia, contra-hegemonia, dominação ou subordinação". Na sua perspectiva, com a qual compartilho, a adoção de uma abordagem fenomenológica, auxiliaria a explicar o âmbito existencial destes, possibilitando uma compreensão mais holística dos mecanismos através dos quais se estruturam os ritos de iniciação na atualidade e a importância destes na perspectiva subjetivas dos praticantes (Cossa, 2014: 32).

Para entender melhor a natureza, contexto e motivações para a realização das práticas vaginais, compreender o seu significado, as percepções sobre os benefícios ou consequências destas práticas, a frequência e a prevalência ao nível da província, foram empregadas abordagens qualitativas e quantitativas. Apesar dos esforços feitos na publicação dos resultados do estudo em Moçambique, sua visibilidade pareceu mais tímida e quase marginal. Maior divulgação, ainda em curso, tem sido particularmente mais evidente a nível internacional em revistas e jornais científicos proeminentes. O limitado reconhecimento institucional ao nível nacional pode-se explicar pelo fato do projeto não ter sido concebido e implementado como parte de uma iniciativa local. Entre acadêmicos, foi percebido como exaltação de um exotismo e reforço de um discurso sobre uma sexualidade perversa, tradicional e inexistente. Este é um ponto de reflexão. Não obstante uma das antropólogas ter nascido em Moçambique, e a outra na Europa, mesmo tendo vivido mais de vinte anos em Moçambique, não era considerada "local", e, por isso, ousava estudar práticas culturais aparentemente tradicionais ultrapassadas. Por outro, as expectativas eram que a antro- 
póloga "local" propusesse temas urbanos e modernos. O paradigma "local" e "não-local" funciona em vários sentidos e serve para excluir pesquisas ou temas que incomodam. $\mathrm{O}$ caso chegou ao ponto de nos advertirem que nos poderiam "cortar a cabeça", acautelando-nos sobre a necessidade de obter autorização do Ministro da Saúde, mediante detalhados esclarecimentos, para além da aprovação (obtida) pelo Comitê Nacional de Ética para a Saúde (CNBS) do Ministério da Saúde (MISAU). O tema em questão era considerado tabu, secreto, privado e íntimo, intersectando relações de poder e de gênero divergentes.

Os profissionais de saúde recomendaram às investigadoras o máximo de atenção metodológica, sensibilidade cultural, uso apropriado da linguagem na comunicação interpessoal e adoção de uma postura ética que não contrariasse e não interferisse com os desejos e as escolhas individuais. A título de exemplo, a Agência das Nações Unidas para o AIDS (UNAIDS) expressou alguma preocupação em relação ao título adotado "práticas vaginais" porque mencionava a "vagina". Apesar de legítimas, as inquietações das instituições, refletem a ideologia e moralidade dominante, que marcam de forma rígida as fronteiras entre os espaços públicos e privados no campo da sexualidade, reforçando e reproduzindo discursos de controle e proteção patriarcalmente motivados (Arnfred, 2015).

Em Moçambique, o estudo foi coordenado e conduzido por duas investigadoras com percursos marcados por experiências e contatos múltiplos de diferentes culturas. Eu, a antropóloga "local", na preparação da pesquisa e nos primeiros dias de trabalho de campo, tinha a convicção de estar preparada para ter o privilégio de pesquisar peculiaridades “íntimas", captar e compreender formas do poder feminino, das relações entre as mulheres, e entre elas e os homens.

Em Tete, no processo de socialização e construção indentitária feminina, o alongamento dos pequenos lábios vaginais constitui um dos aspectos fundamentais da construção do corpo, da sexualidade e do bem-estar. Na interação com as interlocutoras, o fato que nenhuma das duas antropólogas tivesse passado por processos similares aos seus de iniciação à sexualidade criou em algumas interlocutoras perturbação e dúvidas sobre a possibilidade que pudéssemos compreender o mundo das mulheres.

Fomos consideradas "sem vida", "não mulheres" e os nossos corpos incompletos e não preparados, levando-nos a refletir sobre a complexidade do ser nativa e mulher, sobre a construção do corpo e os espaços de poder feminino.

Se a mulher não tiver feito isso [alongamento dos lábios] o homem Ihe abusa, o homem malcriado lhe insulta (...) fala palavras feias, dizendo que você está aberta, não tem vida (...) não tem nada, só tem buraco. (...) O homem zanga e acaba o casamento (Mulher viúva, 64 anos, Tete, agosto de 2005). 


\begin{abstract}
Nós ensinamos as meninas para terem conhecimento, para possuir uma vida, para quando o homem aparecer encontrar em boas condições (...) vida são lábios menores, pegamose puxamos e no fim aquilo chega a crescer (Crupo focal com parteiras tradicionais, mulheres viúvas e casadas em união poligâmica ${ }^{4}$, Tete, agosto de 2005).
\end{abstract}

$\mathrm{Na}$ tentativa de superar as dificuldades de entendimento e nos socializar, assumimos o papel de "iniciandas à sexualidade", aprendendo das mulheres experientes, que agiam como madrinhas-mestres. Conseguimos, assim, aproximar e interagir com as nossas interlocutoras, criando um clima de abertura, confidencialidade e maior interesse na transmissão e partilha de saberes sobre vida e sexualidade.

As experiências relatadas, entre profissionais de saúde, curandeiras, vendedoras ambulantes e dos mercados (de estimulantes sexuais, produtos eróticos, de beleza do corpo), jovens estudantes e madrinhas da iniciação à sexualidade, nem sempre deixaram transparecer a ideia de risco e de nocividade na vida das mulheres, como as antropólogas pressupunham. Tratava-se de cego e ingênuo desconhecimento sobre possíveis implicações das práticas e dos efeitos colaterais dos produtos ingeridos e inseridos nos seus corpos? Ou o pressuposto de nocividade das práticas derivava da nossa inexperiência e desconhecimento, preconceitos simplistas e nossa limitada imaginação? Surpreendentemente, o alongamento dos pequenos lábios é praticado por cerca de 90\% das mulheres (numa amostra representativa de 919 mulheres da província de Tete). Grande parte destas, incluindo profissionais da saúde (enfermeiras e técnicas de medicina) já usaram produtos vaginais para secar, reduzir a lubrificação e apertar a vagina) e não reportaram efeitos negativos. As poucas que narraram efeitos indesejados da aplicação e inserção de produtos químicos e abrasivos (ver Figuras 3 a seguir), referiram-se à lacerações nos lábios vaginais, sensações de ardor, inchaço e secreções vaginais, que na perspectiva objetiva (ética) aumenta a susceptibilidade e vulnerabilidade às infecções de transmissão sexual (ITSs), incluindo o HIV.

As principais motivações, particularmente para ingestão oral e inserção vaginal de produtos, têm a ver com o aumento do prazer sexual masculino e manter

\section{Figura 2}

Investigadora, assistente de pesquisa e vendedora de produtos para tratamento do corpo e sexo. Mercado Kwachena, Tete, 2005 Foto: B.Bagnol.

4 Em diferentes partes de Moçambique, particularmente no sul, em contextos rurais e urbanos, a aliança heterossexual múltipla e concomitante é comum, sendo a prática poligínica, a que consente a um homem ter duas ou mais esposas, a mais difusa. É comum considerar-se este tipo de aliança matrimonial como uma prática ultrapassada, tipicamente rural e tradicional, pacificamente aceita pelos indivíduos envolvidos e socialmente legitimada. Apesar da escassez de documentos que sustentem a ocorrência e difusão da poliginia nas cidades, são inúmeros os casos de relações múltiplas, embora com características e formas estruturais diferentes (Mariano, 2009: 49). 


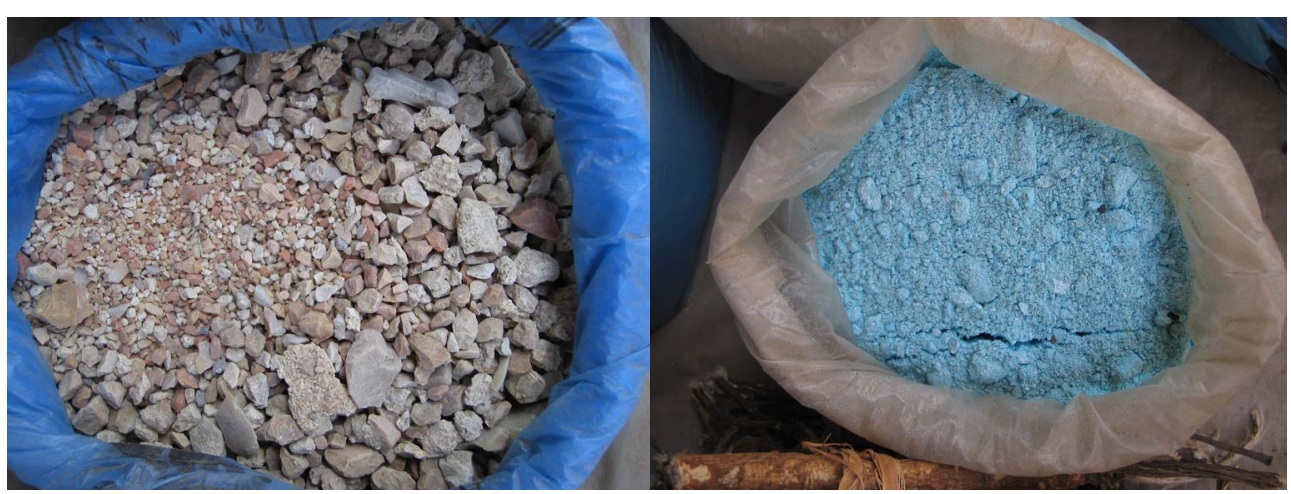

o parceiro comprometido. Os dados quantitativos do "estudo sobre práticas vaginais" indicam que $72 \%$ das mulheres mencionaram que o alongamento dos lábios vaginais é símbolo de identidade feminina, $38 \%$ assinalaram que esta prática é um meio usado para manter o parceiro atraído sexualmente e 35\% informaram que aumenta o prazer sexual masculino (François et al., 2012: 211). É interessante notar que a adoção de procedimentos vaginais para tentar manter um parceiro não é surpreendente, pelo menos na província de Tete, já que quase um terço das mulheres que participaram neste estudo vivia em uma relação estável ou casadas e afirmou que seu parceiro estava envolvido sexualmente com outra mulher (François et al., 2012).

Quando as interlocutoras, num ambiente de alegria, de risos, brincadeiras e de estupefação da nossa ignorância, narravam suas experiências de sexualidade, de preparação dos seus corpos, enfatizando o prazer, o lado positivo da experiência, entre nós, investigadoras, começaram a surgir dúvidas epistemológicas sobre a "subordinação feminina" e sobre o que era possível considerar "nocivo" e "danoso" para a saúde sexual da mulher. É interessante notar as formas de controle dos corpos próprios e dos parceiros, construídas como "segredos das mulheres" por meio de preparados à base de substâncias naturais (nkotheko), para o homem "não esquecer da vagina da mulher", foi mais tarde consensualmente entendida como expressão de poder feminino. Na literatura, o mesmo argumento, é realçado por Signe Arnfred (2015), que evidencia a importância das contra-narrativas, nas quais o prazer, a agência e o poder sexual feminino nos permite descobrir uma tradição viva e uma comunidade de mulheres que se sentem poderosas.

No nosso estudo, a ideia do controle do corpo da mulher sobre o homem foi entendida como mecanismo das mulheres, em primeiro lugar, conquistarem e sucessivamente manterem os parceiros sob seu domínio. Atraindo e seduzindo sexualmente o homem, a mulher recebe em compensação bens materiais e dinheiro (Bagnol e Mariano, 2009: 399), para além de manter estável a relação, limitando o risco de separação. Na mesma linha, no sul de Moçambique, em contextos urbanos da cidade de Maputo, as mulheres usam as "forças da intimidade", como

\section{Figura 3}

Produtos de inserção e aplicação vaginal. Mercado Kwachena, Tete 2005 . Foto: B.Bagnol. 
Croes-Creen as chama, referindo-se às forças mágicas, produtos do e no corpo que objetivam tornar seus parceiros vulneráveis a "se apaixonar", ameaçando o sentido masculino de controle (Groes-Green 2013: 103).

Para a investigadora, que viveu o feminismo dos anos 60 na Europa, os ventos da revolução sexual feminina, rompendo os muros do controle moral e religioso da sociedade burguesa em relação ao corpo, à sexualidade e à reprodução, a experiência destas mulheres em Tete sugeriu ser necessário ultrapassar o paradigma da subordinação universal feminina. As experiências da minha colega, com duas décadas de vivência em Mo-
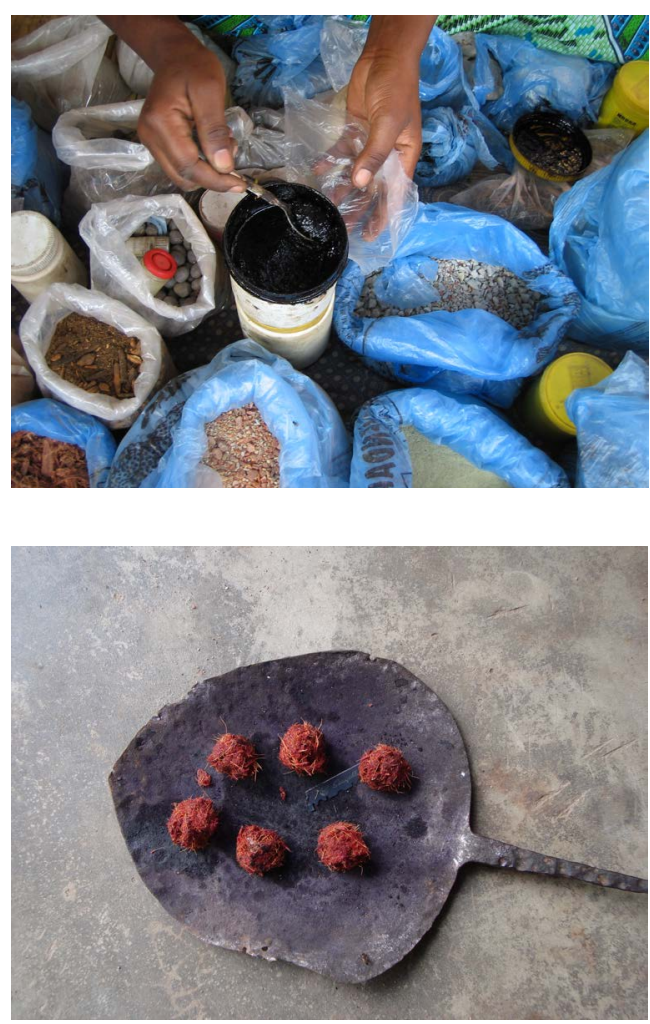
çambique, abertura intelectual em relação à sexualidade, em articulação com a minha, na altura menos informada sobre as teorias feministas euro-norte-americanas, mas socializada com valores e princípios religiosos cristãos, onde o sexo foi silenciado, o prazer sexual e a preparação à sexualidade implicitamente falados, possibilitaram me dar conta da multiplicidade de agências individuais - e de captar as nuances das experiências da sexualidade. Estávamos dispostas a entender o que as mulheres pensam e falam sobre a sexualidade e o significado para elas, sem perder de vista a análise dos equívocos das práticas vaginais.

Entre as mulheres em Tete, o assunto não é tão privado, devido ao fato de que muito da educação sexual e os rituais a ela associados são discutidos entre as mulheres (Bagnol e Mariano, 2009: 399).

Perante esta constatação, senti-me alienada, mas contemporaneamente num espaço e num tempo privilegiado de ressignificação do corpo e de conhecimento sobre ele. Os pressupostos teóricos em relação a uma sexualidade (subordinada), ancorados em sistemas classificatórios, foram se desprendendo no contato com as mulheres em Tete. Na verdade, na esteira de Mbembe,

a teoria social sempre procurou legitimar-se, enfatizando sua capacidade de construir gramáticas universais. Com base nessa afirmação, produziu formas de conhecimento que privilegiam várias categorias que dividem o mundo real, definindo os objetos de indagação, estabelecendo relações de semel hança e equivalências e fazendo classificações (2001: 9-10).

\section{Figura 4}

O creme escuro é usado para o alongamento dos lábios vaginais. Mercado Kwachena, Tete, 2005, Foto: B. Bagnol.

\section{Figura 5}

Produto usado para remoção de secreções vaginais e melhorar a performance sexual. Província de Maputo, 2009. Foto: E. Mariano. 
A referência aos sistemas classificatórios como chaves de leitura do mundo, consciente ou inconscientemente, exerce um certo tipo de autoridade (Mbembe, 2001) em relação ao conhecimento produzido (pelo antropólogo), mas também em relação ao tipo de conhecimento que se tem sobre outros corpos e as sexualidades dos sujeitos-objetos de estudo, eixos de representação que merecem uma atenção cuidadosa.

\section{CONSIDERAÇÕES FINAIS}

Nas diferentes partes deste artigo, de forma contraditória e idiossincrática, percebemos quão escorregadio e impreciso é assumir os termos "local" e "não local", transpostos aos indivíduos como categorias fixas, porque o tempo mostra uma transformação, e a porosidade das fronteiras mostra que o que achamos que pertence a um ou a outro deixa de pertencer. O nome também, como marca de reconhecimento e de identificação social, mostra-se efêmero. É o corpo e são as experiências de quem porta um nome que conferem reconhecimento e interpretam sua existência no mundo, como um ser com múltiplos significados e percursos de trocas com o mundo.

Nestas reflexões, não somente se questiona a autenticidade de ser "nativa", como também as experiências vividas por cada uma de "nós" se cruzam, as quais serviram para apreender e ressignificar os espaços de poder feminino e o posicionamento das instituições (o lugar político) a partir do que intervêm sobre os corpos individuais e sociais. As análises mais críticas das correntes feministas recentes sobre a "política do corpo", discutem e representam o corpo feminino não apenas a partir do discurso médico, religioso e filosófico, mas também em termos de sua plasticidade, como um corpo natural-cultural e como um lugar de contrastes - um corpo poroso, cujas fronteiras são violáveis ou invioláveis, captado nas práticas vaginais.

Em algumas passagens deste texto, observamos que as relações de poder e hierarquia entre o pesquisador e o decisor político são definidas e negociadas constantemente, em função do tema e dos objetivos da investigação. Contrariamente às visões institucionais, as experiências com as mulheres de Tete foram marcadas por uma relação de abertura, em que os corpos delas se abriram para enriquecer o nosso conhecimento com base no respeito e interesse mútuo. Com elas, conseguimos evidenciar dinâmicas de gênero, perceber que existem vários processos de construção de identidades e uma multiplicidade de percepções e conceitos. No percurso de investigação, ficamos gradualmente esclarecidas sobre a relação intrínseca entre sexualidade, processos de construção de valores e mecanismos de controle individual e social existentes, através dos cuidados consigo mesmas. Na verdade, a sexualidade é um campo complexo, cuja plas- 
ticidade depende do olhar do investigador, das suas áreas de conhecimento, dos atores e interlocutores, e que deve ser entendida como fluída e em constante transformação. Minha sensibilidade em quanto mulher, antropóloga, ser humano globalizado permitiu, tentativamente, ultrapassar as dicotomias "local"/"não local" e engajar na construção de um estilo próprio, considerando que "ser antropóloga entre local e global" facilita o acesso não só à dimensão intelectual (cognitiva), mas também às dimensões emotivas e sensoriais, áreas sensíveis e complexas do empreendimento antropológico. A complexidade e o fluxo diário de agências, das representações coletivas dos corpos e entre corpos, requer um posicionamento crítico e desprendido de certas categorias sociais, para, de forma mais aberta possível, entendermos as experiências individuais ao nível imediato, antes da qualquer elaboração teórica ou sistematização conceitual. Metodologicamente, este exercício exige a adoção de uma postura ativa e engajada, capaz de combinar o discurso e a prática por meio das narrativas do investigador e do interlocutor, partilhando e articulando histórias sobre si, "nós" mesmos, e refletindo sobre suas e nossas experiências.

Esmeralda Mariano é Antropóloga Social e Cultural, Professora do Programa de Graduação e de Pós Graduação em Antropologia da Universidade Eduardo Mondlane (UEM), Faculdade de Letras e Ciências Sociais, Departamento de Arqueologia e Antropologia.

\section{REFERÊNCIAS BIBLIOGRÁFICAS}

\section{ARNFRED, Signe}

2015 "Female Sexuality as Capacity and Power? Reconceptualizing Sexualities in Africa". African Studies Review, 58: 149-170 doi:10.1017/asr.2015.78.

APPADURAI, Arjun

1996 Modernity at Large: Cultural Dimensions of Clobalization. Minneapolis/Londres, University of Minnesota Press.

\section{BACNOL, Brigitte}

2006 Cender, Self, Multiple Identities, Violence and Magical Interpretations in Lovolo Practices in Southern Mozambique. Cidade do Cabo, tese de doutorado, University of Cape Town. 
BACNOL, Brigitte e MARIANO, Esmeralda

2008 "Vaginal Practices: Eroticism and Implications for Women's Health and Condom use in Mozambique". Culture, Health and Sexuality 10 (6): 573-585.

2011 "Politics of Naming Sexual Practices." In TAMALE, Sylvia (org.).

African Sexualities. Nairobi, Pambazuka Press, pp. 271-87.

BACNOL, B.; CHERSICH, M.; FRANCOIS, I.;

MBOFANA, F.; MARIANO, E.; e MARTIN-HILBER, A.

2015 "Determinants of Vaginal Cleansing, Application, and Insertion in Tete Province, Mozambique, and Products Used". International Journal of Sexual Health, 0:1-13.

BOUNAN, Michel

2004 Le Tempdu SIDA. Paris, Allia.

COSSA, Segone N.

2014 Corpos ubíquos: um estudo etnográfico sobre a construção social dos corpos em Moçambique. Porto Alegre, dissertação de mestrado, UFRCS.

FIRMINO, Gregório

2008 'Nomes dos vatonga de Inhambane: entre a 'tradição' e a 'modernidade'. Etnográfica, vol. 12 (1): 129-141.

FOUCAULT, Michel

1984 Histoire de la sexualite 3: Le Souci de soi. Paris, Gallimard.

FRANÇOIS, Isabelle; BACNOL, Brigitte; CHERSICH, Matthew; MBOFANA, Francisco; MARIANO, Esmeralda; NZWALO, Hipolito; KENTER, Elise; TUMWESICYE, Nazarius Mbona; HULL, Terry; e HILBER, Adriane Martin 2012 "Prevalence and Motivations of Vaginal Practices in Tete Province, Mozambiqu". International Journal of Sexual Health, 24 (3): 205-217.

GONÇALVES, Marco

1992 "Os nomes próprios nas sociedades indígenas das terras baixas da América do Sul". BIB, Rio de Janeiro, n. 33: 51-72.

COOD, Byron, ].

1994 Narrare la malattia - Lo Sguardo antropologico sul rapporto medico-paziente. Tr. It. Torino, Edizioni di Comunità. 


\section{GROES-GREEN, Christian}

2011 "Philogynous Masculinities: Contextualizing Alternative Manhood in Mozambique". Men and Masculinities, 15 (2): 91-111.

2013 "To Put Men in a Bottle': Eroticism, Kinship, Female

Power and Transactional Sex in Maputo, Mozambique".

American Ethnologist, 40 (1): 102-117.

GUPTA, Akhil e FERGUSON, James

2006 "Beyond 'Culture': Space, Identity and Politics of Difference". In MOORE, Henrietta L. e SANDERS, Todd (orgs.). Anthropology in Theory-Issues in Epistemology. Blackwell Publishing, pp. 608-617.

HONWANA, Alcinda

2002 Espíritos vivos, tradições modernas: possessão de espíritos e reintegração social pós-guerra no sul de Moçambique. Maputo, Promédia.

IMASIDA

2015 Inquérito de indicadores de imunização, malária e HIV/Aids em Moçambique 2014. Moçambique, Ministério da Saúde (MISAU) Instituto Nacional de Estatística (INE).

INE - Instituto Nacional de Estatística

2013 Moçambique: Inquérito Demográfico e de Saúde 2011.

Maputo, Instituto Nacional de Estatística, Ministério da Saúde e MEASURE DHS/ICF International (USA).

KUPER, Adam

2002 "O retorno do nativo". Horizontes Antropológicos, Porto Alegre, ano 8, n. 17: 213-237.

LATOUR, Bruno

1994 Jamais fomos modernos: ensaio de antropologia simétrica. Rio de Janeiro, Editora 34.

LOFORTE, Ana Maria

2003 Práticas culturais em relação à sexualidade e representações sobre saúde e doença. (Comunicação no Workshop sobre os determinantes do HIV/SIDA em Moçambique), Maputo, CEP, UEM. 
MANUEL, Sandra

2009 "Presentes perigosos: dinâmicas de risco de infecção ao HIV/

Aids nos relacionamentos de namoro em Maputo". Physis

Revista de Saúde Colectiva, Rio de Janeiro, 19 (2):371-386.

MARIANO, Esmeralda

2005 "Narrare l'Aids: Rompere il muro del silenzio". In

MORELLI, Gabriella Mondardini (org.). Drammi del corpoe

narrazioni su di essi. Italia, Cagliari University Press.

MARIANO, Esmeralda e BACNOL, Brigitte

2009 "Interventions on Women's Body and the Impact on their Sexual and Reproductive Health". Revista Médica de Moçambique, v. 10: 27-36.

MARIANO, Esmeralda; BAGNOL, Brigitte; FRANÇOIS, Isabelle; $\mathrm{CHERSICH}$, Matthew; MBOFANA, Francisco; e HILBER, Adriane Martin

2011 "Vaginal Practices in Tete Province, Mozambique: Qualitative and Quantitative Research/Práticas vaginais na província de Tete: pesquisa qualitativa e quantitativa". Maputo, Eduardo Mondlane University / International Centre for Reproductive Health (ICRH).

\section{MATSINHE, Cristiano}

2005 Tábula rasa: dinâmicas da resposta moçambicana ao HIV/SIDA. Maputo, Texto Editores.

MBEMBE, Achille

2001 "As formas africanas de auto-inscrição". Estudos

Afro-Asiáticos, ano 23, n. 1:172-209.

2016 Politiques de l'inimité. Paris, Éditions la Découverte.

MONDLANE, Eduardo

1995 Lutar por Moçambique. Maputo, Coleção Nosso Chão.

\section{MINISTÉRIO DA SAÚDE}

2005 Rela tório sobre a revisão dos dados de vigilância epidemiológica do HIV ronda 2004. Moçambique, Direção Nacional de Saúde. Programa Nacional de Controle das DTS/SIDA. 
MUNANGA, Kabengele

2013 "A antropologia brasileira diante da hegemonia ocidental e as possibilidades de aplicação da antropologia no mercado de trabalho". Revista de Antropologia, São Paulo, USP, v. 56, n. 1.

NARAYAN, Kirin

1993 "How Native Is a 'Native' Anthropologist?". American

Anthropologist, New Series, vol. 95, n. 3: 671-686.

NKWI, N. Paul

2008 "La antropología en una África poscolonial: el debate de supervivencia". In RIBEIRO, Gustavo Lins e ESCOBAR, Arturo (orgs.). Antropologías del mundo: transformaciones disciplinarias dentro de sistemas de poder. Colombia, Wenner-Cren Foundation for Anthropological Research, Envión Editores.

OHNUKI-TIERNEY, Emiko

1984 "Native Anthropologist". American Ethnologist, vol. 11, n. 3: 584-586.

PINA CABRAL, João

2008 "Outros nomes, histórias cruzadas: apresentando o debate". Etnográfica, vol 12 (1): 5-16.

SCHEPER-HUGHES, Nancy

2000 "Il Sapere incorporato: Pensare con il corpo attraverso un'antropologia medica critica". In BAROFSKY, Roberto (org.). Antropologia culturale oggi. Roma, Meltemi.

TRAJANO FILHO, Wilson

2008 "O trabalho da crioulização: as práticas de nomeação na Guiné colonial". Etnográfica, vol. 12 (1): 95-128.

VIVEIROS DE CASTRO, Eduardo

2010 "O nativo relativo". MANA, 8 (1): 113-148. 


\section{On Being Local and Clobal Anthropologist}

\section{ABSTRACT}

This article explores the unfolding and complexity of being "local" and "global" anthropologist in an effort to overcome the dichotomous paradigm resulting from historical and political processes that place social actors in delimited and localized spaces. These aspects are explored from the history of my name, combining intersubjective experiences and reflexivity in sexuality research in contexts of Mozambique.
KEYWORDS

Native

Anthropologist, Local and Clobal, Subjective Experiences

Recebido em 30 de maio de 2017. Aceito em 6 de novembro de 2017. 